\title{
WHAT THE MOUTH HAS TO SAY ABOUT DIABETES IN A NIGERIAN TERTIARY HOSPITAL
}

\author{
Ogunmuyiwa $\mathrm{SA}^{1}$, Adesina $\mathrm{OF}^{2}$, Alalade $\mathrm{BA}^{2}$. Otukoya $\mathrm{OA}^{2}$, Adewusi $\mathrm{FT}^{2}$, Olukunle $\mathrm{OG}^{2}$, Bello \\ $\mathrm{AO}^{3}$. \\ ${ }^{1}$ Oral and Maxillofacial Surgery unit, Federal Medical Centre, Abeokuta, Nigeria \\ ${ }^{2}$ Endocrinology and Diabetes unit, Federal Medical Centre, Abeokuta, Nigeria \\ ${ }^{3}$ Nursing Department, Federal Medical Centre, Abeokuta, Nigeria
}

Introduction: The mouth is said to be the body's mirror. Diabetes can be associated with the development of various types of disorders within the oral cavity of which Periodontal disease is about the commonest and may indeed be the first manifestation of diabetes. Oral manifestations of diabetes are many and include burning mouth syndrome, candidiasis, dental caries, gingivitis, glossodynia, periodontitis, salivary dysfunction and parotid gland enlargement, taste dysfunction and xerostomia among others. Apart from being considered as the sixth complication of diabetes, it has been shown that severe periodontal disease increases the risk of nephropathy, stroke, transient ischaemic attack, angina and myocardial infarction.

Aim: To evaluate the oral health of individuals with diabetes at Federal Medical Centre, Abeokuta, Nigeria.

Methodology: Descriptive study carried out between January and December 2014. The findings during the annual dental examination in each patient with diabetes were documented alongside their $\mathrm{HbA} 1_{\mathrm{C}}$ levels.

The World Health Organization Community Periodontal Index was used to assess the periodontal health status of patients as follows:

Score $0=$ healthy periodontal conditions

Score 1 = gingival bleeding

Score 2 = gingival bleeding and calculus

Score 3 = shallow periodontal pockets ( 4 to $5 \mathrm{~mm}$ )

Score $4=$ deep periodontal pockets $(\geq 6 \mathrm{~mm})$

Results: 103 patients comprising of 45 males (43.6\%) and 58 females (56.4\%) participated in the study. Age ranged between 18 - 89 years with mean age of $57.14 \pm 13.06$ years. Duration of Diabetes was between 1 month and 30 years with a mean duration of 6 years while mean $\mathrm{HbA} 1 \mathrm{c}$ was $66.1 \mathrm{mmol} / \mathrm{mol}$ with a range of $22.4 \mathrm{mmol} / \mathrm{mol}-130.6 \mathrm{mmol} / \mathrm{mol}$.

$15.5 \%$ had healthy periodontium, while $84.5 \%$ had various periodontal disorders. Sixty-six percent of those with periodontal disease had HbA1c greater than $53 \mathrm{mmol} / \mathrm{mol}$.

$56.3 \%$ had mild gingivitis, $40.8 \%$ had moderate gingivitis while $2.9 \%$ had severe gingivitis. Of these, only $30.1 \%$ had HbA1c greater than $53 \mathrm{mmol} / \mathrm{mol}$. 
$39.8 \%$ had missing teeth; $29.1 \%$ had between 1 and 4 teeth missing, while $10.7 \%$ had between 5 and 15 teeth missing. There was significant association between Diabetes duration and missing teeth, $\mathrm{p}=0.002$.

Discussion: oral lesions in diabetes are associated with the state of glycaemic control and disease duration. Higher glycosylated haemoglobin levels were associated with varying degrees of periodontal disease. Periodontitis may contribute to poor glycaemic control and poor glycaemic control may increase the severity of periodontitis. This bi-directional relationship which has been proven in literature is also shown in this study. There was a strong association between duration of diabetes and number of missing teeth in this study.

Conclusion: Good oral health is now one of the accepted strategies in achieving glycaemic control in diabetes. Annual oral examinations in individuals with diabetes are therefore of great value in early identification and management of oral complications that follow diabetes.

\section{References}

1. Ship JA. Diabetes and oral health: an overview. J Am Dent Assoc 2003; 134: 4S-10S.

2. Grossi SG, Skrepcinski FB, DeCaro T, et al. Treatment of periodontal disease in diabetics reduces glycated haemoglobin. J Periodontol. 1997; 68: 713-719.

3. Darré L, Vergnes JN, Gourdy P et al. Efficacy of periodontal treatment on glycaemic control in diabetic patients: A meta-analysis of interventional studies. Diabetes Metab 2008; 34: 497-506.

4. Peterson PE, Ogawa H. Strengthening the prevention of periodontal disease: The WHO Approach. J Periodontol 2005; 76:2187-2193.

5. Löe H. Periodontal disease: the sixth complication of diabetes mellitus. Diabetes Care 1993; 16: $329-334$ 